3. Bukatov, V. M. "Drama-Hermeneutics as an Innovative Element in the Modern Development of Domestic Didactics." Vestnik Tverskogo Gosudarstvennogo Universiteta. Pedagogika y Psichologia, no. 3, 2015, pp. 128-139.

4. Vartanova, V. V. "Arrangement of Educational Environment in Professional Language Training by Means of Theatrical Activities." Mnogoyazychiye v Obrazovatyelnom Prostranstve. Pedagogika. Lingvodidaktika, vol. 2, 2009, pp. 106-109.

5. Yezhov, P. Yu. Formation of the Playing Culture of the Children of Primary School Age by Interactive Means of Theatricalization: Doctoral Dissertation. Saint-Petersburg, 2014, 197 p.

6. Dneprov, S. A., Demina, A. Yu. "Pedagogical Opportunities of the Principle of Theatricalization in Formation of Moral Values of Junior Schoolchildren." Pedagogicheskoye Obrazovaniye $v$ Rossii, no. 1, 2008, pp. 146-153.

7. Shayakhmetova, L. Kh., Mukhametzyanova, L. R. "Technology of Dramatization as a Creative Method of Teaching English as a Foreign Language (with an Example of a Special Course "English Theatre.”) Mediterranean Journal of Social Sciences, no. 3, 2015, pp. 296-300.

8. Athiemoolam, L. Drama-in-Education and Its Effectiveness in English Second and Foreign Language Classes. Oldenburg, 2004, 18 p.

9. Billikova, A., Kiššova, M. Drama Techniques in the Foreign Language Classroom. London, 2013, $136 \mathrm{p}$.

10. Dowdy, J. K., Gao, Y. "Using Drama to Engage English Learners in Literacy Activity." Ohio Reading Teacher, no. 1, 2014, pp. 28-34.

11. Petrusevich, P. Yu. "Conditions of Teaching Two Foreign Languages in the System of School Education." Problemy Sovremennogo Pedagogicheskogo Obrazovaniya, no. 59-1, 2018, pp. 277-281.

12. Solovova, E. N. Methodology of Teaching Foreign Languages: Basic Course of Lectures. Moscow, 2002, $239 \mathrm{p}$.

13. Amonashvili, Sh. A. Humane-Personal Basics of Pedagogical Process. Minsk, 1990, 560 p.

14. Sukhomlinskiy, V. A. Selected Pedagogical Essays. Moscow, vol. 1, 1979, 560 p.

15. Semenova, E. V., Semenov, V. I. "Development Opportunities of Training Students' English Theatre in Pedagogical High School." Fundamentalnye Issledovaniya, no. 9, 2014, pp. 2068-2072.

16. Petrusevich, P. Yu. Methodology of Formation of Lexical Competence of School Pupils While They Learn Several Foreign Languages: Doctoral Dissertation. Nizhniy Novgorod, 2019, 195 p.

УДК 371.263:376.684(485) (045)

\title{
Рубинов Е.
}

Центр интегращии и многоязычия, Соллентуна, Стокгольмский округ (Швеция)

\section{КАРТИРОВАНИЕ ЗНАНИЙ И УМЕНИЙ ВНОВЬ ПРИБЫВШИХ В ШВЕЦИЮ ШКОЛЬНИКОВ-ИММИГРАНТОВ}

Швеция является одной из стран, принимающих наибольшее количество беженцев и других категорий иммигрантов. В последние десятилетия в шведской системе школьного образования находится достаточно большая группа детей, которые одновременно изучают новый язык и приобретают на этом языке новые знания и навыки. Продолжающийся процесс миграции заставляет шведскую систему образования реагировать на вызовы, связанные с необходимостью интегрировать в кратчайшие сроки достаточно многочисленную группу учеников, не владеющих шведским языком и навыками обучения в шведской школе.

Ученики-иммигранты в Швеции представляют собой достаточно неоднородную группу с различными уровнями подготовки, опыта и потребностей. Министерство образования Швеции считает, что необходимо улучшить условия для интеграции вновь прибывших учеников в шведскую школьную систему с помощью более четкого определения их потребностей. С января 2016 г. министерством образования было введено обязательное педагогическое картирование опыта, знаний и навыков вновь прибывших учеников как в области владения языком, так и по отдельным школьным предметам. С этой целью были разработаны соответсвующие материалы. 
Картирование должно проходить в течение первых двух месяцев обучения ученика, и его результатом должен явиться профиль знаний и умений, который будет использован для определения места ученика в шведской школьной системе и планирования его дальнейшего обучения. Статья описывает подходы и методы, применяемые в данном картировании, а также двойную роль учителя родного языка как учителя-предметника и как медиатора между школой, учеником и его семьей в ходе интеграционного процесса.

Ключевые слова: Швеция, ученики-иммигранты, интеграция, картирование знаний и умений, навыки чтения и понимания текста, развитие устной и письменной речи в условиях билингвизма.

Сведения об авторе:

Рубинов Евгения, учитель русского языка и координатор Центра интеграции и многоязычия, (Соллентуна, Стокгольмский округ, Швеция).

DOI: $10.35634 / 2500-0748-2019-11-14-21$

\section{Введение}

Швеция является одной из стран, принимающих наибольшее количество беженцев и других категорий иммигрантов. Они приезжают преимущественно из стран Ближнего Востока, Азии, Латинской Америки, а также из России, Украины и других стран постсоветского пространства. По критериям шведского министерства образования, вновь прибывшим считается ученик, приехавший в Швецию в возрасте, с которого образование становится обязательным (6 лет). После 4 лет пребывания в стране ученик перестает считаться вновь прибывшим.

Продолжающаяся миграция заставляет шведскую систему образования реагировать на вызовы, связанные с необходимостью интегрировать в кратчайшие сроки достаточно многочисленную группу учеников, не владеющих шведским языком и навыками обучения в шведской школе.

Цель статьи - ознакомить русскоязычных читателей с принципами и методами работы шведской образовательной системы в области интеграции вновь прибывших учеников. Необходимо отметить, что эта проблематика чрезвычайно часто обсуждается в Швеции как в научном сообществе, так и на страницах общественно-политических изданий и в многочисленных теле- и радиопередачах. Результаты международных исследований указывают на падение уровня знаний у шведских школьников, и частично это происходит в результате недостаточно успешной интеграции учеников, прибывших из других стран.

Разрыв в образовательном уровне прибывающих из разных стран учеников и его частое несоответствие принятым в Швеции образовательным стандартам и критериям признается одной из серьезнейших причин последующего социального неравенства и, как следствие, напряженности в отношениях между различными слоями населения. Таким образом, выработка адекватных решений непростой задачи по включению учеников-иммигрантов в образовательный процесс стала в Швеции одной из центральных тем не только педагогических дискуссий, но и предвыборных политических дебатов.

\section{1. Причины появления метода картирования}

Как уже было сказано, ученики-иммигранты в Швеции представляют собой достаточно неоднородную группу с различными уровнями подготовки, опыта и потребностей. Она включает в себя как детей приглашенных на работу в Швецию программистов, врачей и ученых, так и детей, переживших войну и пропустивших несколько лет школьного обучения из-за невозможности ходить в школу. Некоторые из них не умеют читать и писать на своем родном языке.

Учителя в шведских школах часто не имеют достаточного представления о языковом и когнитивном развитии вновь прибывших учеников. Они обращают внимание прежде всего на слабые стороны таких учеников и делают выводы об их знаниях только на основании их недостаточного владения шведским языком [Skolverket, 2014]. Министерство образования 
считает, что необходимо улучшить условия для интеграции вновь прибывших учеников в шведскую школьную систему с помощью более четкого определения их потребностей [Skolinspektionen, 2014]. С этой целью были разработаны материалы для картирования опыта, знаний и навыков вновь прибывших учеников как в области владения языком, так и по отдельным школьным предметам на основе аналогичных материалов, созданных в Норвегии. С января 2016 г. все школы Швеции, принимающие вновь прибывших учениковиммигрантов обязаны проводить подробное педагогическое картирование их опыта, знаний и навыков как в области владения языком, так и по отдельным школьным предметам.

\section{2. Методика проведения картирования}

Картирование должно проходить в течение первых двух месяцев обучения ученика, и его результатом должен явиться профиль знаний и умений, который будет использован для определения места ученика в шведской школьной системе и планирования его дальнейшего обучения.

Обычно первые этапы картирования проводится в специальном центре по приему учеников-иммигрантов, который также отвечает за помощь вновь прибывшим ученикам в течение нескольких первых лет в стране и за преподавание им родного языка. В таких центрах есть специально назначенный педагог, отвечающий за картирование. Он договаривается с родителями ученика и приглашает их вместе с ребенком на собеседование, в ходе которого объясняет, как работает шведская система образования и для чего проводится данное картирование.

В ходе предварительного собеседования выясняются особенности языкового развития ученика, его опыт по изучению новых языков, а также история его школьного обучения в стране исхода и мнение родителей об успешности этого обучения. Ученики и их родители также имеют возможность задать вопросы и рассказать о своих ожиданиях, связанных с началом учебы в шведской школе.

В ходе картирования предполагается определить:

- степень готовности ученика к занятиям в рамках шведской школьной системы;

- уровень развития навыков чтения и письма, а также знание родного языка;

- примерный уровень знаний по основным школьным предметам, владение основными понятиями и навыками решения задач.

Картирование навыков чтения и письма занимает примерно два часа, в ходе которых необходимо предоставить ученику перерыв как минимум в 15 мин. для того, чтобы он смог отдохнуть и поговорить с родителями. Родители на картировании присутствовать не обязаны, обычно они ждут своего ребенка возле комнаты, в которой проходит картирование. В некоторых случаях, если ребенок очень застенчивый, сильно волнуется или еще достаточно маленький, можно попросить кого-то из родителей участвовать в картировании. Однако их необходимо предупредить о том, что помогать ребенку с заданиями не надо, это только повредит при анализе результатов. И ученики, и родители должны понимать, что картирование не является экзаменом и проводится с единственной целью: проинформировать принимающую школу об уровне подготовки ученика для того, чтобы для него смогли подобрать подходящую программу обучения. Ученик не должен волноваться изза возможных неудач, обстановка во время картирования должна быть спокойной и доброжелательной.

В ходе картирования навыков чтения и письма ученик получает тексты для чтения и письменные задания. Вначале проверяется знание букв как латинского, так и родного алфавита, затем идет проверка навыков чтения слов и предложений, после чего ученик получает короткие тексты и вопросы для проверки понимания прочитанного. Степерь сложности текстов постепенно возрастает. Если выясняется, что ученик еще не умеет читать, фокус картирования смещается в сторону понимания на слух. С помощью учителя родного языка ученик должен прослушать текст и ответить на вопросы по пониманию услышанного. 
Картирование на родном языке должно помочь оценить, насколько владение ученика шведским языком развито по отношению к его уровню владения родным языком, а также определить, необходима ли ученику дополнительная помощь или обследование у специалиста, например, по различным нарушениям чтения и письма. Если при картировании выясняется, что ученик отстает в языковом развитии на родном языке, подобные сложности, скорее всего, появятся у него и при изучении шведского языка [Salameh, 2003].

\section{3. Основные трудности детей-иммигрантов при адаптации к системе шведского обучения}

Картирование знаний и умений вновь прибывшего ученика на родном языке поможет также выявить различия в требованиях, предъявляемых в шведской школе и в системе обучения той страны, из которой он прибыл. Ученик должен получить возможность показать не только свой запас знаний, но и то, каким образом он привык их приобретать и применять.

В шведской школе в программные требования по основным школьным предметам входит умение применять знания на практике в различных ситуациях и контекстах, в то время как в школах некоторых других странах иногда делается больший акцент на теоретические знания. Часто вновь прибывшие ученики отличаются от выросших в шведской системе тем, что не умеют работать в группе, самостоятельно планировать свою работу над определенной темой или искать по ней информацию.

В шведской школе также высоко ценится способность критически относиться к разного рода информации и выражать личное мнение. В некоторых других странах ученики могут быть наказаны за выражение собственного мнения и за критический анализ содержания текстов. Целью чтения и письма в некоторых странах может выступать последующее заучивание текста наизусть, зазубривание его содержания и написание текстов по памяти, в то время как в шведской школе ценится способность прочитывать тексты «между строк» и умение их перерабатывать, выделяя самое главное [Sandell, Hassanpour, 2013]. Существуют также различия между тем, каким образом ученик привык писать / читать на родном языке и тем, что от него ожидается на уроках в шведской школе. Например, в младших классах русской школы до сих пор уделяется большое внимание умению писать прописными буквами, в то время, как в шведской начальной школе большинство письменных заданий выполняется на компьютере, и развитие мелкой моторики не предполагает обучения умению правильно держать ручку или карандаш.

Ученики, обучавшиеся в другом школьном контексте незнакомого для них материала, часто будут встречаться в шведской школе с текстами, созданными на основе отсутствующего у них опыта и неизвестных им понятий [Sandell, Hassanpour, 2013]. При этом текстом считается не только письменная речь, но и ее комбинации с другими визуальными элементами, такими как фото, диаграммы или художественные иллюстрации, переданные с помощью различных носителей, например, на экране компьютера или телевизора. Очень важно, чтобы учителя-предметники были в курсе того, что как содержание, так и тип текстов и иллюстраций к ним могут быть неизвестны некоторым ученикам.

Следующий этап картирования связан с проверкой владения основными математическими понятиями и навыками решения задач. Обычно эта часть картирования проводится учителем, знакомым с преподаванием математики в шведской школе. Ученики получают вопросы и задачи, связанные как с абстрактными математическими действиями, так и с применением их на практике, в реальной жизни. Именно это отличает преподавание математики в шведской школе от того, как формулируются задачи обучения математике во многих других странах. В Швеции на уроках математики большое внимание уделяется переводу задач, выраженных в словесной форме, на язык формул, умению самостоятельно сформулировать вопрос, найти на него ответ и объяснить, каким образом было принято решение. 


\section{4. Работа с результатами картирования}

После проведения картирования производится анализ собранных материалов, который должен являться основой, как для учебного планирования, так и для последующего выставления оценок. Педагог, ответственный за картирование, должен заполнить специальный бланк с профилем ученика, в котором он суммирует результаты картирования и выводы о степени готовности ученика к участию в учебном процессе. Особое внимание должно уделяться сильным сторонам подготовки ученика, акцент делается на тех знаниях и умениях, которые помогут ему адаптироваться к новой учебной системе.

Педагог, ответственный за картирование, также обязан дать рекомендации по определению ученика в соответствующий класс, хотя последнее слово здесь остается за директором школы. В основном, в Швеции принят принцип определения учеников в класс, подходящий им по возрасту, однако достаточно часто ученики-иммигранты попадают в класс с детьми, которые младше их примерно на год. Это мотивируется необходимостью подучить язык и смягчить стресс от перехода в новую учебную систему, однако некоторые наиболее амбициозные родители могут быть недовольны таким решением.

Педагог, проводивший картирование, посещает школу, в которую направляется вновь прибывший ученик и встречается с будущим классным руководителем и представителями администрации школы для того, чтобы передать им результаты картирования и все остальные необходимые документы. Теперь за адаптацию ученика отвечает школа. Обычно ученик начинает обучение в специальной группе для вновь прибывших, где интенсивно преподается шведский язык. Однако с самого начала у него уже есть класс, в который он записан и классный руководитель, который за него отвечает. Ученик должен ходить на некоторые уроки вместе со своим классом, это могут быть уроки пения или физкультуры, а также английского или математики, если знания ученика позволяют это сделать. Последний этап картирования - проверка уровня знаний по предметам естественно-научного и общественно-социального циклов проводится уже на месте, в школе, учителямипредметниками с привлечением учителей родного языка.

\section{5. Роль учителя родного языка в организации картирования}

В процессе картирования обязательно должен принимать участие учитель родного языка, с помощью которого ученик сможет адекватно выразить свои мысли и показать все свои когнитивные, языковые и социальные способности и навыки. Он также помогает передавать всю значимую информацию об обучении в шведской школе родителям ученика, как устно, так и посредством специально подготовленных брошюр, переведенных на все основные языки приезжающих в Швецию иммигрантов. Материалы картирования переведены на многие языки, в том числе и на русский.

Учитель родного языка должен проинформировать других учителей в школе о том, на какой ступени вновь прибывший ученик находится в своем языковом развитии. Также важно предоставить им информацию о том, какие навыки и стратегии развиты у этого ученика, чтобы учителя смогли учитывать эти данные при планировании своих уроков. Получение четкой картины языкового развития ученика и его знаний по различным предметам может потребовать значительного времени, особенно, если он начинает обучение в Швеции в старших классах средней школы.

В настоящее время после завершения картирования учителя родного языка обычно встречаются с вновь прибывшими учениками один или два раза в неделю в течение 60-120 мин. Они приходят на уроки и помогают ученику разобраться в новых понятиях и терминах на шведском языке, а также служат связующим звеном между учеником, его родителями и школой. Учитель родного языка может выступать как в качестве учителя-предметника, составляющего профиль знаний ученика по родному языку, так и в качестве переводчика для других учителей-предметников. Иногда он и сам проводит картирование по различным предметам в соответствии с пожеланиями коллег [Skolverket, 2014]. 
Таким образом, учителя родного языка в Швеции выступают в двойной роли: в учебное время они помогают ученикам по различным предметам, а после уроков проводят занятия по сохранению родного языка. Эти уроки для учеников бесплатные. Учитель также получает небольшой бюджет на закупку учебных пособий и книг. К сожалению, новые требования по картированию не привели к пересмотру существующих норм педагогической нагрузки. Время, выделяемое на помощь вновь прибывшим ученикам, постоянно сокращается. Нередко учителя родного языка проводят вспомогательные занятия по разным предметам в больших группах, что не способствует хорошему усвоению материала.

На уроках родного языка учителя стараются предоставить ученику тексты на разных уровнях и в разных жанрах: отрывки из учебников, газетные статьи, литературные произведения. Учитель может проследить за тем, какие понятия ученик использует в устной и письменной речи, насколько он способен находить в тексте нужную информацию и пересказывать ее другим. Позволяя ученику писать, читать и обсуждать прочитанное на родном языке, можно изучить его словарный запас, владение грамматикой, умение создавать собственные тексты. Учитель должен проанализировать несколько текстов, написанных учеником, а также несколько раз прослушать, как ученик читает или выражает свои мысли в устной форме, для того, чтобы оценить, насколько успешно ученик использует язык в качестве инструмента для коммуникации в различных контекстах и ситуациях. Можно также сделать аудиозапись чтения вслух или говорения ученика для того, чтобы впоследствии было легче анализировать отдельные лингвистические компоненты его речи.

Все учителя, работающие с вновь прибывшими детьми, должны быть проинформированы учителем родного языка о том, чем отличается опыт данного ученика в области чтения и письма от принятого в шведской школе. Учителя всегда должны думать о том, какие именно тексты они используют в обучении и о заданиях, которые при этом даются. Они должны задаваться вопросами: какой тип чтения, поиска и интерпретации информации будут применяться на уроке, и какие трудности это может представлять для вновь прибывших учеников. На уроках родного языка следует также посвятить много времени работе с различными видами текстов для того, чтобы ученики развивали ключевые стратегии и навыки, которые они затем смогут использовать на других уроках.

\section{Заключение}

Предварительное картирование знаний и умений вновь прибывшего ученика при успешном взаимодействии учителей-предметников и учителей родного языка в идеале должно являться основой планирования индивидуального развития учеников-иммигрантов в рамках шведской школьной системы. В реальности эффективность такого планирования зависит от условий работы в каждой конкретной школе и от степени заинтересованности каждого конкретного учителя. Автор статьи не ставила целью собрать данные по поводу русских детей, хотя неоднократно участвовала в подобных картированиях как в качестве учителя родного языка, так и в качестве координатора всего процесса. Чтобы собирать данные для подобного анализа, требуется разрешение родителей и этической комиссии, и это может стать темой отдельного исследования. Можно лишь поделиться личными наблюдениями: дети из России обычно показывают хорошие или очень хорошие результаты по чтению и письму, но некоторые разделы заданий по математике иногда ставят их в тупик, поскольку в таком разрезе эти темы в российской школе, видимо, не изучаются. Я бы не хотела акцентировать внимание на том, как выглядят показатели российских детеймигрантов на фоне учеников, прибывших из других стран, но российские родители не всегда довольны тем, что детей определяют в класс соответственно возрасту или классом ниже. У детей, прибывших из зоны военных действий в Сирии или в Афганистане, чаще всего возникают проблемы несколько иного рода... .

Поводя итоги, можно отметить искреннее желание шведских властей и сотрудников шведской системы образования облегчить вновь прибывшим ученикам интеграцию в новой стране и в новой школе. Все понимают, что это нелегкий процесс, особенно когда речь идет 
о семьях, не привыкших к систематическому контролю за развитием и обучением своих детей. Нелегко в этом процессе и учителям. Работая с гетерогенными группами, в которых есть также дети с психоневрологическими диагнозами, они должны учитывать присутствие в классе иноязычных учеников и адаптировать свой стиль преподавания к их возможностям и потребностям. Именно для этого и было задумано предварительное картирование знаний и умений вновь прибывших учеников. Однако никто пока не проверял степень эффективности этого процесса в облегчении планирования работы с вновь прибывшими учениками. Неизвестно, насколько часто результаты картирования используются учителямипредметниками и классными руководителями при составлении индивидуального плана для каждого конкретного ученика. Будем надеяться, что результаты большой работы как педагогов, так и самих учеников не останутся бесполезными, и вместо того, чтобы пылиться на полке в школьном сейфе, они действительно помогут ученикам быстрее интегрироваться в учебный процесс на новом языке.

\title{
Литература:
}

1. Nilsson, J., Axelsson, M. "Welcome to Sweden...: Newly Arrived Students' Experiences of Pedagogical and Social Provision in Introductory and Regular Classes." International Electronic Journal of Elementary Education, vol. 6(1), 2013, pp. 137-64.

2. Salameh, E. K. Language Impairment in Swedish Bilingual Children-Epidemiological and Linguistic Studies. Lund University Hospital, 2003, 181 p.

3. Sandell, R. A., Hassanpour, A. "Pedagogisk kartläggning av nyanlända elever." Symposium 2012. 2013. Stockholm, pp. 97-113.

4. Skolinspektionen. Utbildningen för Nyanlända Elever. Kvalitetsgranskning 2014, http://www.skolinspektionen.se/sv/Beslut-och-rapporter/Publikationer/Granskningsrapport/ Kvalitetsgranskning/Utbildningen--for-nyanlanda--elever-2014.

5. Skolverket. Behovsinventering Inför Kompetens ut vecklings ins atser för Kartläggning av Nyanländas Kunskaper, http://www.skolverket.se/publikationer?id=3258.

6. Skolverket. Kartläggningsmaterial för Nyanlända Elever, https://bp.skolverket.se/ web/step_2/start.

DOI: $10.35634 / 2500-0748-2019-11-14-21$

\author{
Rubinov E. \\ Centre for Integration and Multilingualism in the Municipality of Sollentuna, \\ Stockholm Region, Sweden
}

\section{MAPPING THE KNOWLEDGE AND SKILLS OF NEWLY ARRIVED IMMIGRANT SCHOOLCHILDREN IN SWEDEN}

Sweden is one of the countries hosting the largest number of refugees and other categories of immigrants. In recent decades, the Swedish school system has been entered by a sizeable group of children who are at the same time learning a new language and acquiring new knowledge and skills in this language. The ongoing migration forces the Swedish education system to respond to the challenges associated with the need to integrate as soon as possible a fairly large group of students who do not speak Swedish and study at a Swedish school.

The immigrant students in Sweden are a rather heterogeneous group with different levels of training, experience and needs. The Swedish National Agency for Education believes that it is necessary to improve the conditions for the integration of newly arrived students in the Swedish school system by better defining their needs. Since January 2016 an obligatory pedagogical mapping both of the newly arrived students' language skills and of their knowledge in different school subjects has been introduced by the Swedish National Agency for Education. To this end, materials have been developed for mapping the experience, knowledge and skills of newly arrived students both in the field of language proficiency and in individual school subjects.

The mapping should take place during the first two months of a student's learning, and the result should be a profile of knowledge and skills that will be used to determine the students' place 
in the Swedish school system and plan their further education. The article presents the approaches and methods used during this mapping, as well as the dual role of the mother tongue teacher as both a subject teacher and as a mediator between the school, the student and the family during the integration process.

Key words: Sweden, immigrant students, integration, mapping of knowledge and skills, decoding and reading comprehension skills, oral and written speech development in bilingual settings.

About the author:

Rubinov Evgenia, Russian Teacher and Coordinator of the Centre for Integration and Multilingualism in the Municipality of Sollentuna, (Sollentuna, Stockholm Region, Sweden).

\section{References:}

1. Nilsson, J., Axelsson, M. "Welcome to Sweden...: Newly Arrived Students' Experiences of Pedagogical and Social Provision in Introductory and Regular Classes." International Electronic Journal of Elementary Education, vol. 6(1), 2013, pp. 137-64.

2. Salameh, E. K. Language Impairment in Swedish Bilingual Children - Epidemiological and Linguistic Studies. Lund University Hospital, 2003, 181 p.

3. Sandell, R. A., Hassanpour, A. "Pedagogisk kartläggning av nyanlända elever." Symposium 2012. 2013. Stockholm, pp. 97-113.

4. Skolinspektionen. Utbildningen för Nyanlända Elever. Kvalitetsgranskning 2014, http://www.skolinspektionen.se/sv/Beslut-och-rapporter/Publikationer/Granskningsrapport/ Kvalitetsgranskning/Utbildningen--for-nyanlanda--elever-2014.

5. Skolverket. Behovsinventering Inför Kompetens ut vecklings ins atser för Kartläggning av Nyanländas Kunskaper, http://www.skolverket.se/publikationer?id=3258.

6. Skolverket. Kartläggningsmaterial för Nyanlända Elever, https://bp.skolverket.se/ web/step_2/start. 